University of Nebraska - Lincoln

DigitalCommons@University of Nebraska - Lincoln

Faculty Publications, Department of Physics and Astronomy

Research Papers in Physics and Astronomy

2010

\title{
Magnetic and optical properties of multiferroic $\mathrm{GdMnO}_{3}$ nanoparticles
}

\author{
X. L. Wang \\ Chinese Academy of Sciences, 72 Wenhua Road, Shenyang 110016, People's Republic of China \\ D. Li \\ Chinese Academy of Sciences, 72 Wenhua Road, Shenyang 110016, People's Republic of China \\ T. Y. Cui \\ Chinese Academy of Sciences, 72 Wenhua Road, Shenyang 110016, People's Republic of China \\ Parashu Kharel \\ University of Nebraska - Lincoln, pkharel2@unl.edu \\ W. Liu \\ Chinese Academy of Sciences, 72 Wenhua Road, Shenyang 110016, People's Republic of China \\ See next page for additional authors
}

Follow this and additional works at: https://digitalcommons.unl.edu/physicsfacpub

Part of the Physics Commons

Wang, X. L.; Li, D.; Cui, T. Y.; Kharel, Parashu; Liu, W.; and Zhang, Z. D., "Magnetic and optical properties of multiferroic $\mathrm{GdMnO}_{3}$ nanoparticles" (2010). Faculty Publications, Department of Physics and Astronomy. 88.

https://digitalcommons.unl.edu/physicsfacpub/88

This Article is brought to you for free and open access by the Research Papers in Physics and Astronomy at DigitalCommons@University of Nebraska - Lincoln. It has been accepted for inclusion in Faculty Publications, Department of Physics and Astronomy by an authorized administrator of DigitalCommons@University of Nebraska Lincoln. 


\section{Authors}

X. L. Wang, D. Li, T. Y. Cui, Parashu Kharel, W. Liu, and Z. D. Zhang 


\title{
Magnetic and optical properties of multiferroic $\mathrm{GdMnO}_{3}$ nanoparticles
}

\author{
X. L. Wang, ${ }^{1}$ D. Li, ${ }^{1, a)}$ T. Y. Cui, ${ }^{1}$ P. Kharel, ${ }^{2}$ W. Liu, ${ }^{1,2}$ and Z. D. Zhang ${ }^{1}$ \\ ${ }^{1}$ Shenyang National Laboratory for Materials Science, Institute of Metal Research, and International Centre \\ for Materials Physics, Chinese Academy of Sciences, 72 Wenhua Road, Shenyang 110016, People's \\ Republic of China \\ ${ }^{2}$ Department of Physics and Astronomy and Nebraska Center for Materials and Nanoscience, University \\ of Nebraska, Lincoln, Nebraska 68588-0113, USA
}

(Presented 19 January 2010; received 29 October 2009; accepted 5 December 2009; published online 29 April 2010)

The magnetic and optical properties of multiferroic $\mathrm{GdMnO}_{3}$ nanoparticles synthesized by a polymerized complex method have been investigated. The $\mathrm{GdMnO}_{3}$ nanoparticles crystallized in orthorhombic perovskite-type structure. The zero-field-cooled and field-cooled magnetizations show that complicated magnetic transitions occur in a temperature range from 2 to $60 \mathrm{~K}$, which were confirmed by magnetic hysteresis loops. Three shoulder absorption peaks centered at about 2.0, 2.3, and $2.7 \mathrm{eV}$ are attributed to the $\mathrm{Mn}(3 \mathrm{~d})$-electronic transitions, while an absorption peak at around $4.1 \mathrm{eV}$ corresponds to the charge-transfer transitions between $\mathrm{O}(2 \mathrm{p})$ and $\mathrm{Mn}(3 \mathrm{~d})$ states. UV emission at about 396 and $406 \mathrm{~nm}$ and blue emission at around $466 \mathrm{~nm}$ have been found, which may be attributed to the spin-allowed charge-transfer transitions. (c) 2010 American Institute of Physics. [doi:10.1063/1.3358007]

\section{INTRODUCTION}

Multiferroics with significant magnetoelectric coupling effect have been widely investigated because of their attractive physical mechanism and potential applications in data storage and sensors. ${ }^{1-4}$ The single-phase $\mathrm{RMnO}_{3}(\mathrm{R} \equiv \mathrm{a}$ trivalent rare-earth ion, such as $\mathrm{Tb}$, Dy, and $\mathrm{Gd}$ ) perovskite manganites have attracted more attention in recent years because strongly competing magnetic interactions play a very important role in inducing a magnetoelectric effect. ${ }^{5-10}$ Bulk $\mathrm{GdMnO}_{3}$ has metamagnetic features with a transition from antiferromagnetic to weak-ferromagnetic state upon cooling and the antiferromagnetic alignments of $\mathrm{Gd}$ sublattice below $6 \mathrm{~K}^{11}$ Investigation on a single crystal $\mathrm{GdMnO}_{3}$ shows a significant anisotropy with a strong increase in magnetization along the c-axis at about $20 \mathrm{~K}$, indicating a canted state of the spontaneous magnetization. ${ }^{12}$ Recently, attention has been focused on optical properties of single crystals and films of the manganites, proving that characteristic energy scales are related to corresponding physical phenomena. The electronic structure of the manganites has a close relationship with their crystal structure, specially the distance between $\mathrm{Mn}$ and $\mathrm{O}$ atoms. ${ }^{13-16} \mathrm{It}$ is well known that the nanosized materials may exhibit unique electrical, magnetic, and optical properties far different from those of their bulk counterparts because of low dimensionality and quantum confinement effect. ${ }^{17}$ In this work, we study the magnetic and optical properties of $\mathrm{GdMnO}_{3}$ nanoparticles.

\section{EXPERIMENTAL PROCEDURE}

$\mathrm{GdMnO}_{3}$ nanoparticles were synthesized by a polymerized complex method described elsewhere. ${ }^{18}$ All reagents are commercial ones in analytical purity, which were used with-

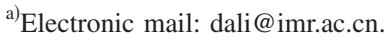

out further purification. A solution was prepared by mixing aqueous solution of $\mathrm{Mn}\left(\mathrm{NO}_{3}\right)_{2}$ and $\mathrm{Gd}\left(\mathrm{NO}_{3}\right)_{3}$ in 1:1 molar ratio and then citric acid was added with stirring. When the solution was adjusted to $p \mathrm{H} \sim 6$ by adding dilute ammonial solution under stirring, the cations of $\mathrm{Mn}^{2+}$ and $\mathrm{Gd}^{3+}$ were complexed into their citrates. Then, ethylene glycol was added to make gelation. The molar amounts of citric acid and ethylene glycol were twice that of $\mathrm{Gd}$ and Mn cations. Excess citric acid and ethylene glycol can prevent nucleation and inhibit the growth of the nuclei, which can induce a preferable size distribution. The solution was stirred at room temperature for $5 \mathrm{~h}$ and heated at $100{ }^{\circ} \mathrm{C}$ until a gel was formed. This gel was further dried in oven at $130^{\circ} \mathrm{C}$ and grounded into fine black powders. Finally, black precursor powders were calcined in air atmosphere at 700, 800, and $900{ }^{\circ} \mathrm{C}$ for $5 \mathrm{~h}$, respectively.

The phase analysis for all the products was performed by using powder $\mathrm{x}$-ray diffraction (XRD) on a D/max-2000 diffractometer with $\mathrm{Cu} K \alpha$ radiation at $56 \mathrm{kV}$ and $182 \mathrm{~mA}$. The averaged grain size of the powder was estimated from the (111) reflection by means of the Scherer equation. Morphology was investigated by a Supra 35 field-emission scanning electron microscope (SEM) equipped with energy-dispersive spectrum (EDS) operated at an acceleration voltage of $20 \mathrm{kV}$. Magnetic properties were measured by a superconducting quantum interference device (Quantum Design). UV spectra were recorded with a Hitachi UV-3010 spectrophotometer with a scan speed of $1200 \mathrm{~nm} / \mathrm{min}$. Fluorescence spectra were recorded with a Hitachi F-4500 spectrophotometer equipped with a xenon lamp using the excitation wavelength of $270 \mathrm{~nm}$.

\section{RESULTS AND DISCUSSION}

Figure 1 exhibits XRD patterns of the $\mathrm{GdMnO}_{3}$ precursors calcined at different temperatures. The main phase of 


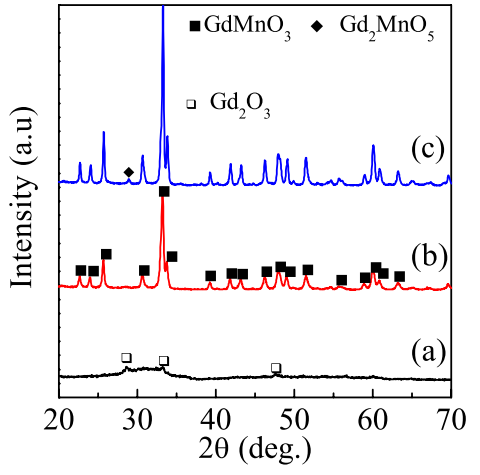

FIG. 1. (Color online) XRD patterns of the $\mathrm{GdMnO}_{3}$ precursors calcined at (a) $700{ }^{\circ} \mathrm{C}$, (b) $800{ }^{\circ} \mathrm{C}$, and (c) $900{ }^{\circ} \mathrm{C}$ for $5 \mathrm{~h}$.

the sample calcined at $700{ }^{\circ} \mathrm{C}$ in an amorphous state mixed with a small amount of $\mathrm{Gd}_{2} \mathrm{O}_{3}$. When the precursors are calcined at $800{ }^{\circ} \mathrm{C}$, a single phase $\mathrm{GdMnO}_{3}$ with orthorhombic structure is obtained. With increasing the calcination temperature up to $900{ }^{\circ} \mathrm{C}$, a small amount of $\mathrm{GdMn}_{2} \mathrm{O}_{5}$ appears. The morphology of the $\mathrm{GdMnO}_{3}$ nanoparticles obtained at $800{ }^{\circ} \mathrm{C}$ was observed by SEM, as shown in Fig. 2(a). The averaged particle size of the assembled nanoparticles is estimated to be $52 \mathrm{~nm}$, a little larger than its averaged grain size of $31 \mathrm{~nm}$. In order to determine the chemical composition of the $\mathrm{GdMnO}_{3}$ nanoparticles, an EDS spectrum was recorded. Figure 2(b) shows that main elements in our sample are Gd, $\mathrm{Mn}$, and $\mathrm{O}$ with $\mathrm{Gd}$ to $\mathrm{Mn}$ molar ratio of about 1:1, close to the nominal concentration. The unmarked peaks $\mathrm{C}$ and $\mathrm{Cu}$ in Fig. 2(b) are originated from the sample grid.

Figure 3 shows the zero-field-cooled (ZFC) and fieldcooled (FC) magnetization curves of $\mathrm{GdMnO}_{3}$ nanoparticles recorded at an applied field of 100 Oe between 2 and $60 \mathrm{~K}$.

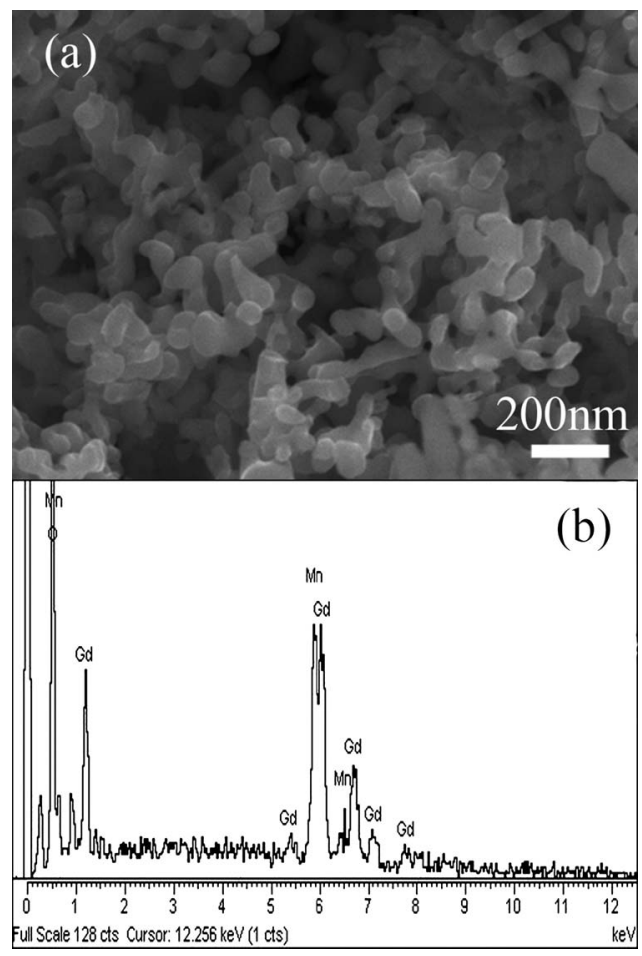

FIG. 2. (a) High-magnification SEM and (b) EDS images of the $\mathrm{GdMnO}_{3}$ nanoparticles.

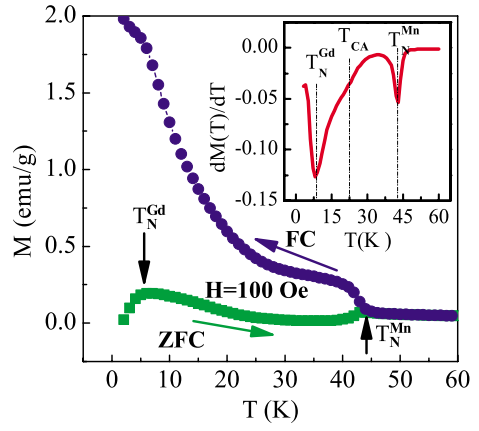

FIG. 3. (Color online) ZFC and FC magnetization curves of the $\mathrm{GdMnO}_{3}$ nanoparticles at an applied field $\mathrm{H}=100$ Oe between 2 and $60 \mathrm{~K}$. Inset: temperature dependence of the derivative $\mathrm{dM} / \mathrm{dT}$.

In the present nanoparticles, complicated magnetic transitions take place in the vicinity of the transition temperatures of the bulk and/or single crystal $\mathrm{GdMnO}_{3}$, corresponding to the sine wave ordering of $\mathrm{Mn}^{3+}$ moments and magnetic ordering of $\mathrm{Gd}^{3+}$ moments, respectively. ${ }^{7,11}$ The transition temperatures are determined by the numerical derivative $\mathrm{dM}(\mathrm{T})$ / $\mathrm{dT}$, as shown in the inset of Fig. 3. Neutron diffraction analysis indicated that Néel temperature $\left(\mathrm{T}_{\mathrm{N}}^{\mathrm{Mn}}\right)$ in $\mathrm{TbMnO}_{3}$ is $\sim 40 \mathrm{~K} .{ }^{19}$ The $\mathrm{T}_{\mathrm{N}}^{\mathrm{Mn}}$ of $\mathrm{GdMnO}_{3}$ should be larger than that of $\mathrm{TbMnO}_{3}$ because the $\mathrm{T}_{\mathrm{N}}^{\mathrm{Mn}}$ for rare-earth orthoferrites, vanadites, titanites, and chromites increases with increasing radius of the lanthanon. ${ }^{11}$ In Fig. 3, a paramagneticantiferromagnetic transition at about $44 \mathrm{~K}$ indicates the $\mathrm{T}_{\mathrm{N}}^{\mathrm{Mn}}$ for a configuration of $\mathrm{Mn}$ moments in $\mathrm{GdMnO}_{3}$. With decreasing the temperature, an increase of magnetization is observed at around $20 \mathrm{~K}$ due to an appearance of weak ferromagnetism, which may be contributed by the canting of Mn moments and the polarization of the Gd $4 \mathrm{f}$ spins. ${ }^{12}$ At $7 \mathrm{~K}$, due to the interaction of the $4 \mathrm{f}$ spins, the long-range order of Gd moments appears, resulting in a configuration of a net moment of canted Gd spins antiparallel to that of canted Mn spins.

Figure 4 represents the hysteresis loops of $\mathrm{GdMnO}_{3}$ nanoparticles recorded at different temperatures after a ZFC process. The paramagnetic behavior of the $\mathrm{GdMnO}_{3}$ nanoparticles is found in the loops at 50 and $60 \mathrm{~K}$. With decreasing the temperature, an antiferromagnetism is observed at about $30 \mathrm{~K}$ in $\mathrm{GdMnO}_{3}$ nanoparticles, in agreement with the phase transition at $\mathrm{T}_{\mathrm{N}}^{\mathrm{Mn}}$ around $44 \mathrm{~K}$. With further decreasing the temperature, a weak-ferromagnetic behavior is found at

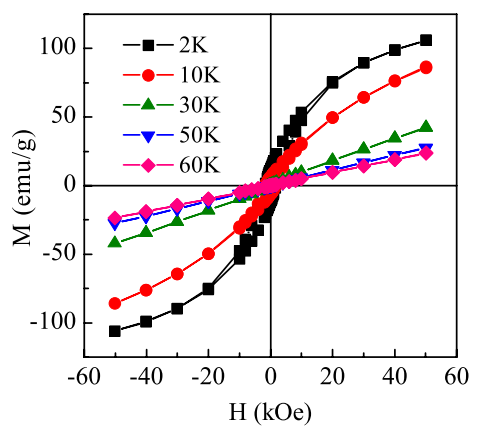

FIG. 4. (Color online) Hysteresis loops of the $\mathrm{GdMnO}_{3}$ nanoparticles recorded at different temperatures. 


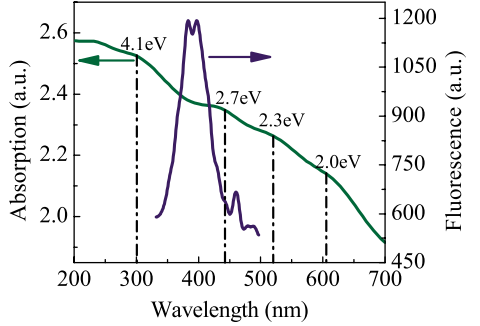

FIG. 5. (Color online) Absorption and fluorescence spectra of the $\mathrm{GdMnO}_{3}$ nanoparticles.

about $10 \mathrm{~K}$, due to the spin canting of the Mn moments and the polarization of the $\mathrm{Gd} 4 \mathrm{f}$ spins. ${ }^{12}$ At $2 \mathrm{~K}$, the contribution of the net moment of the $\mathrm{Gd}$ spins is larger than that of the antiferromagnetically canted state of the Mn spins, giving rise to a ferromagneticlike loop because the external magnetic field aligns the $\mathrm{Gd}$ moments. ${ }^{12}$

The absorption and fluorescence spectra of the $\mathrm{GdMnO}_{3}$ nanoparticles are shown in Fig. 5. At room temperature, the absorption spectra in a range of wavelength between 400 and $700 \mathrm{~nm}$ consist of three shoulder peaks centered at about 2.0, 2.3 , and $2.7 \mathrm{eV}$, which are attributed to the $\mathrm{Mn}(3 \mathrm{~d}$ )electrons' transition. ${ }^{20-23}$ On the other hand, the higher energy absorption peak centered around $4.1 \mathrm{eV}$ should be associated with the manifold of charge-transfer transitions between $\mathrm{O}(2 \mathrm{p})$ and $\mathrm{Mn}(3 \mathrm{~d})$ states. $^{23-25}$ The ultraviolet emission with peaks around 396 and $406 \mathrm{~nm}$, as well as a blue band emission with peak around $466 \mathrm{~nm}$ are also observed due to the spin-allowed charge transfer transitions.

\section{CONCLUSION}

In conclusion, the magnetic and optical properties of the multiferroic $\mathrm{GdMnO}_{3}$ nanoparticles have been investigated. The magnetization measurements show that complicated magnetic transitions take place in the present nanoparticles, very similar to the case of the bulk (and/or single crystal) $\mathrm{GdMnO}_{3}$, while the saturation magnetization of about 106 $\mathrm{emu} / \mathrm{g}$ is smaller than the value of $125 \mathrm{emu} / \mathrm{g}$ for the bulk $\mathrm{GdMnO}_{3}$ at $2 \mathrm{~K}$. Absorption peaks for $\mathrm{GdMnO}_{3}$ nanoparticles centered at about 2.0,2.3, and $2.7 \mathrm{eV}$ originates from the Mn (3d)-electrons' transition, while the absorption peak centered at $4.1 \mathrm{eV}$ is associated with the manifold of chargetransfer transitions between $\mathrm{O}(2 \mathrm{p})$ and $\mathrm{Mn}(3 \mathrm{~d})$ states. The multiple UV emissions and a blue band emission are attributed to the spin-allowed charge transfer transitions.

\section{ACKNOWLEDGMENTS}

This work has been supported by the National Natural Science Foundation of China (No. 50831006 and 50701045) and by the National Major Fundamental Research Program of China (No. 2010CB934603), the Ministry of Science and Technology of China. Research at Nebraska (P.K.) was supported by NSF-mrsec (DMR-0820521) and NCMN, USA.

${ }^{1}$ T. J. Park, G. C. Papaefthymiou, A. J. Viescas, A. R. Moodenbaugh, and S. S. Wong, Nano Lett. 7, 766 (2007).

${ }^{2}$ P. Zhao, Z. L. Zhao, D. Hunter, R. Suchoski, C. Gao, S. Mathews, M. Wuttig, and I. Takeuchi, Appl. Phys. Lett. 94, 243507 (2009).

${ }^{3}$ L. Yan, Z. P. Xing, Z. G. Wang, T. Wang, G. Y. Lei, J. F. Li, and D. Iehlamd, Appl. Phys. Lett. 94, 192902 (2009).

${ }^{4}$ M. Mostovoy, Phys. Rev. Lett. 96, 067601 (2006).

${ }^{5}$ R. Feyerherm, E. Dudzik, A. U. B. Wolter, S. Valencia, O. Prokhnenko, A. Maljuk, S. Landsgesell, N. Aliouane, L. Bouchenoire, S. Brown, and D. N. Argyriou, Phys. Rev. B 79, 134426 (2009).

${ }^{6}$ A. Pimenov, A. A. Mukhin, V. Y. Ivanov, V. D. Travkin, A. M. Balbashov, and A. Loidl, Nat. Phys. 2, 97 (2006).

${ }^{7}$ T. Kimura, G. Lawes, T. Goto, Y. Tokura, and A. P. Ramirez, Phys. Rev. B 71, 224425 (2005)

${ }^{8}$ T. Kimura, T. Goto, H. Shintani, K. Ishizaka, T. Arima, and Y. Tokura, Nature (London) 426, 55 (2003).

${ }^{9}$ T. Goto, T. Kimura, G. Lawes, A. P. Ramirez, and Y. Tokura, Phys. Rev. Lett. 92, 257201 (2004).

${ }^{10}$ J. L. Ribeiro, Phys. Rev. B 76, 144417 (2007).

${ }^{11}$ O. Y. Troyanchuk and N. V. Kasper, Low Temp. Phys. 23, 300 (1997).

${ }^{12}$ J. Hemberger, S. Lobina, H. A. Krug von Nidda, N. Tristan, V. Y. Ivanov, A. A. Mukhin, A. M. Balbashov, and A. Loidl, Phys. Rev. B 70, 024414 (2004).

${ }^{13}$ J. I. Takahashi, K. Kohn, and E. Hanamura, J. Lumin. 100, 141 (2002).

${ }^{14}$ M. W. Kim, S. J. Moon, J. H. Jung, J. Yu, S. Parashar, P. Murugavel, J. H. Lee, and T. W. Noh, Phys. Rev. Lett. 96, 247205 (2006).

${ }^{15}$ W. S. Choi, D. G. Kim, S. A. Seo, S. J. Moon, D. Lee, J. H. Lee, H. S. Lee, D. Y. Cho, Y. S. Lee, P. Murugavel, J. Yu, and T. W. Noh, Phys. Rev. B 77, 045137 (2008).

${ }^{16}$ P. Gao, T. A. Tyson, Z. Liu, M. A. Deleon, and C. Dubourdieu, Phys. Rev. B 78, 220404 (2008).

${ }^{17}$ Y. G. Wang, G. Xu, Z. H. Ren, X. Wei, W. J. Weng, P. Y. Du, G. Shen, and G. R. Han, J. Am. Ceram. Soc. 90, 2615 (2007).

${ }^{18}$ S. G. Wang, A. M. Chang, H. M. Zhang, and Q. Zhao, Mater. Chem. Phys. 110, 83 (2008).

${ }^{19}$ R. Kajimoto, H. Yoshizawa, H. Shintani, T. Kimura, and Y. Tokura, Phys. Rev. B 70, 012401 (2004).

${ }^{20}$ K. Tobe, T. Kimura, Y. Okimoto, and Y. Tokura, Phys. Rev. B 64, 184421 (2001).

${ }^{21}$ V. Perebeinos and P. B. Allen, Phys. Rev. Lett. 85, 5178 (2000).

${ }^{22}$ N. N. Kovaleva, A. V. Boris, C. Bernhard, A. Kulakov, A. Pimenov, A. M. Balbashov, G. Khaliullin, and B. Keimer, Phys. Rev. Lett. 93, 147204 (2004).

${ }^{23}$ M. W. Kim, P. Murugavel, S. Parashar, J. S. Lee, and T. W. Noh, New J. Phys. 6, 156 (2004).

${ }^{24}$ J. H. Jung, K. H. Kim, D. J. Eom, T. W. Noh, E. J. Choi, J. Yu, Y. S. Kwon, and Y. Chung, Phys. Rev. B 55, 15489 (1997).

${ }^{25}$ M. W. Kim, J. H. Jung, K. H. Kim, H. J. Lee, J. Yu, T. W. Noh, and Y. Moritomo, Phys. Rev. Lett. 89, 016403 (2002). 